\title{
Forgiveness and Conflict Resolution in Close Relationships: Within and Cross Partner Effects"
}

Perdón y resolución de conflictos en relaciones cercanas:
efectos intra y entre parejas

Recibido: febrero 5 de 2009 ｜ Revisado: agosto 20 de 2009 ｜Ａceptado: septiembre 1 de 2009

\author{
F. GIORgIA PALEARI ${ }^{* *}$ \\ University of Bergamo, Italy \\ CAMILlO Regalia ${ }^{* * *}$ \\ Catholic University of Milan, Italy \\ FRANK D. FINCHAM ${ }^{* * * *}$ \\ Florida State University, USA
}

* Research article.

** Correspondence concerning this article should be addressed to F. Giorgia Paleari, Dept. of Language, Communication and Cultural Studies, University of Bergamo, piazzale S. Agostino 2, 24129 Bergamo, Italy. Correo electrónico: francesca-giorgia. paleari@unibg.it

*** Camillo Regalia, Dept. of Psychology, Catholic University of Milan, Italy.

Correo electrónico: camillo.regalia@unicatt.it

${ }^{* * * * *}$ Frank D. Fincham, Family Institute, Florida State University.

Correo electrónico: ffincham@fsu.edu

\section{A B S T R A C T}

Do forgiveness and conflict tactics (compromise, aggression, and avoidance) in response to conflicts instigated by a romantic partner's offence uniquely predict effective arguing and relationship quality? Using 92 Italian couples we tested a mediational model in which each partner's responses to conflict predicted both partners' perceived effective arguing that, in turn, predicted their own relationship quality. For both men and women, negative responses to conflict (unforgiveness, aggression, and avoidance) overlapped and jointly predicted self-reported and partner-reported relationship quality, directly and indirectly via effective arguing. Positive responses investigated (benevolence and compromise) did not overlap for either men or women. Men's positive responses to conflict uniquely predicted self-reported and partnerreported relationship quality via effective arguing, whereas women's positive responses did not predict them independently of their male partner's tactics. Key words authors

Forgiveness, Conflict, Partner Relationships.

Key words plus

Partner Relationships, Marital Conflict, Conflict Management.

\section{RES U MEN}

¿Sirven las tácticas de perdón y conflicto (compromiso, agresión y evitación) en respuesta a conflictos propiciados por un miembro de la pareja, como predictores únicos y efectivos de las conversaciones y la calidad de las relaciones? Con 92 parejas italianas se probó un modelo mediacional en el cual las respuestas de cada compañero al conflicto predecía las conversaciones efectivas, que a su vez predecían la calidad de la relación. Para hombres y mujeres, las respuestas negativas al conflicto (no perdonar, agredir y evitar) se traslaparon y predijeron la calidad de la relación reportada por ellos mismos y por sus parejas, directa e indirectamente a través de la conversación efectiva. Las respuestas positivas investigadas (benevolencia y compromiso) no se traslaparon ni para hombres ni para mujeres. Las respuestas positivas de los hombres al conflicto predijeron la calidad de la relación reportada por ellos y por sus parejas.

Palabras clave autores

Perdón, conflicto, relaciones de pareja.

Palabras clave descriptor

Relaciones de pareja, conflicto marital, solución de conflictos. 


\section{Introduction}

A growing body of evidence attests to the potential benefits of interpersonal forgiveness for the well-being of close relationships. Forgiveness has been shown to reduce psychological aggression and facilitate relational closeness and prorelationship responses following a partner's transgression (Eaton \& Struthers, 2006; Karremans \& Van Lange, 2004; McCullough, Rachal, Sandage, Worthington, Brown \& Hight, 1998; Park \& Enright, 1997). In community couples forgiveness towards the partner is associated with restored relational closeness and satisfaction, and positive interactions following an interpersonal transgression (e.g., Fincham, 2000; Gordon \& Baucom, 2003; Kachadourian, Fincham \& Davila, 2004). There is also evidence that forgiving the partner enhances intimacy and commitment in the relationship, promotes constructive communication, and has a positive influence on marital quality over time (Fincham \& Beach, 2002; Paleari, Regalia \& Fincham, 2005; Tsang, McCullough \& Fincham, 2006). Finally, after controlling for concurrent socio-cognitive processes, forgiveness predicts later marital quality more strongly than marital quality predicts later forgiveness (Paleari et al., 2005).

Although the beneficial effects of forgiveness for relational well-being are now well documented, the mechanisms through which these effects occur are largely unknown. How does forgiveness strengthen the relationship? In view of evidence that relationship satisfaction and stability are affected by partners' perceived efficacy in managing couple arguments (e.g., Fincham, Harold \& Gano-Phillips, 2000; Kurdek, 1994), one potential mechanism that might be involved is the perceived ability to effectively handle arguments. In fact, Fincham, Beach, and Davila (2004) showed that forgiveness dimensions predict perceived efficacy in managing conflicts. Husbands who were less unforgiving had wives who reported more effective arguing during conflicts. Conversely, wives who were more benevolent in response to a partner transgression had husbands who reported higher levels of effective arguing. Thus, as Beach, Kamen and Fincham (2006) state, forgiveness is likely to help arguing couples move "from a trajectory dominated by vicious cycles to one protected by self-regulating, constructive feedback loops" (p. 31). The purpose of the current investigation was to determine whether the forgiveness - relationship quality association is mediated by the perceived ability to effectively handle arguments.

\section{Forgiveness as a way of resolving conflicts}

Forgiveness has been typically defined as a way to deal with offences (or transgressions or injuries) rather than as a way to deal with conflicts (see for example McCullough, Pargament \& Thoresen, 2000). Within this literature, offences and conflicts are assumed to be conceptually distinct. Offences entail significant damages to the individual, specifically to his or her view of the self, and/or to core beliefs about the availability and trustworthiness of others (Feeney, 2005). In contrast, conflicts are social interactions, in which the partners hold incompatible goals, interests, wishes, expectations or differing opinions, and can range from mild divergences in preferences or views to severe verbal and physical fights (Beach, 2001; Bradbury, Rogge \& Lawrence, 2001). Thus conflicts, especially minor ones, do not necessarily cause the degree of personal damage that offences do and consequently do not necessarily require forgiveness (e.g., disagreeing about where to go on holidays is properly not perceived as a hurt necessitating forgiveness).

Notwithstanding this viewpoint, both laypeople and scientists often assume that forgiveness can play an important role in effectively managing interpersonal conflicts. For example, several scholars (e.g., Barber, Maltby \& Macaskill, 2005; Karremans, Van Lange, Ouwerkerk \& Kluwer, 2003; Lawler, Younger, Piferi, Billington, Jobe, Edmondson \& Jones, 2003; Park \& Enright, 1997; Zechmeister \& Romero, 2002) have argued that forgiveness might be helpful in understanding how individuals view and cope with interpersonal conflicts. As previously noted, this assumption is 
supported by recent empirical evidence showing that that forgiving the spouse promotes more effective conflict resolution (Fincham et al., 2004).

Why can forgiveness be properly regarded as a conflict resolution strategy as well as a response to offences? An answer arises from recognition of the fact conflicts and offences are especially likely to co-occur in daily life. Specifically, conflicts lead to offences whenever a partner says things or enacts behaviors that the other person perceives as hurtful or insulting. Similarly offences tend to engender conflict especially when they are committed against close others. In the context of close relationships, offences often result in overt verbal communication. Because of the divergent views held by the transgressor and the victim of the offence (Feeney \& Hill, 2006), these verbal exchanges can easily result in conflicts. An effective way to handle these conflicts may be to forgive the initial offence that gave rise to the conflict. Accordingly, we argue that forgiving the partner may be properly regarded as a way of handling couple conflicts when the conflict originates from a partner offence.

\section{Forgiveness and other conflict resolution strategies}

According to Veroff, Young, and Coon (1997), research on couple conflict has traditionally focused on three strategies that are used to handle conflict: constructive engagement (e.g., compromise, negotiation, problem solving) characterized by open, direct communication which takes into account both partners interests; destructive engagement (e.g., aggression, coercion), that is, "attacks" toward a partner involving criticism, hostility, and dominance; and avoidance (withdrawal), evidenced by ignoring or denying the problem and avoiding confrontation, which primarily has negative effects when too frequently applied (e.g., Leonard \& Roberts, 1998; Goeke-Morey, Cummings, Harold \& Shelton, 2003). All of these strategies have been conceptualized as behaviors intended to manage or resolve conflict, which includes all partner commissions and omissions in response to perceived or actual disagreement (Klein \& Johnson, 1997).
Are there any similarities between forgiveness and the above strategies?

Forgiveness has been conceptualized as an intrapersonal phenomenon, involving changes in thoughts, feelings and motivations toward the offender. Nonetheless many scholars agree that these changes must manifest themselves in overt behaviors in order to be genuine (Enright et al., 1998; Fincham, 2000; Rye \& Pargament, 2002). In other words, motivational, affective and cognitive changes cannot constitute forgiveness in the absence of concomitant behavioral changes. Accordingly, some of the scales developed to measure forgiveness include behavioral components (e.g. the Enright Forgiveness Inventory, Subkoviak et al., 1995). Thus, like conflict strategies, forgiveness can be viewed as involving the behavioral system, even though it cannot be reduced to behaviors only.

The above theoretical considerations apply to both dimensions of forgiveness, namely, unforgiveness (negative dimension) and benevolence (positive dimension). Unforgiveness refers to persistent negative reactions towards the offender like avoidant, revengeful or resentful thoughts, feelings, motivations, and behaviors. Conversely, benevolence involves the presence of conciliatory thoughts, feelings, motivations, and behaviors towards the offender towards whom the victim shows an attitude of goodwill (Fincham, Hall \& Beach, 2006).

However it must be noted that the behaviors forgiveness entails are more frequently captured empirically by the negative dimension of the construct than by the positive dimension. This possibly happens because the benevolence dimension of forgiveness seems to be less clearly characterized by specific overt behaviors that have a definite topography (Fincham, 2000). Moreover, unforgiveness can be readily deduced by the presence of avoidant and revengeful behaviors toward the offender, whereas benevolence cannot be inferred by the presence of overt positive behaviors toward the offender (e.g., public gestures of pacification), since they can reflect motives other than forgiveness (e.g., fear of retaliation, convenience). 
It is also important to note that the avoidant and vengeful behaviors studied in forgiveness research are so similar to the avoidant and destructive strategies investigated in the couple conflict literature that they can be assumed to overlap. This is readily apparent in examining operationalizations of the constructs in the two literatures. For example, the TRIM (Transgression Relevant Interpersonal Motivations, McCullough et al., 1998) and the MFS (Marital Forgiveness Scale, Fincham et al., 2004) assess unforgiveness through items (e.g., "I keep as much distance between us as possible", "I withdraw from him/her", "I'm going to get even", "I retaliated or did something to get my own back") which are very similar to items found in the CRSI (Conflict Resolution Style Inventory; Kurdek, 1994), the MCI (Marital Coping Inventory; Bowman, 1990) and the CI (Conflict inventory; Kahn, Coyne \& Margolin, 1985) that are used to measure avoidant and aggressive conflict strategies (e.g., I'm "withdrawing, acting distant, and not interested", "I decide to get even with my partner", "I plan revenge").

Notwithstanding this similarity, a conceptual distinction can be made between them on the following grounds. First, unforgiveness includes intrapersonal features, such as feelings, thoughts, and motivations, whereas conflict tactics do not. Second, unforgiveness can not be properly considered a tactic to resolve conflict when the conflict represents disagreement without the commission of hurt or damage, that is, when no offence occurred. Thus we argue that in specific circumstances, namely, when conflicts are instigated by offences, the avoidant and aggressive behavioral strategies investigated by conflict researchers are confounded with the avoidant and revengeful behavioral component of unforgiveness. Therefore, in these circumstances avoidant and aggressive strategies can be viewed as embedded in a broader unforgiving response.

The positive behaviors entailed in the benevolence dimension of forgiveness, however, are more likely to be distinct from (and not confounded with) the compromising and negotiating constructive strategies investigated in the couple conflict literature. Being benevolent does not necessarily imply compromise: one can be forgiving and tolerant without wavering on one's position. Contrariwise compromising does not necessarily reflect conciliatory thoughts, feelings, and intentions. For instance, one can search for a compromise simply to avoid an aversive escalation of the conflict, with no real interest in showing a forgiving attitude towards the partner.

In light of these observations, the present study investigated forgiveness in relation to conflict strategies like aggression, avoidance, and compromise, when conflicts were instigated by partner offences. Specifically, it investigated whether forgiveness and conflict strategies (aggression, avoidance, and compromise) each predict relational outcomes (i.e., perceived effective arguing and, indirectly, relationship quality) when the other was controlled.

\section{Overview of the present study}

Forgiveness and conflict have rarely been examined concurrently within the context of couple relationships (for an exception see Fincham et al., 2004). Consequently, this study had two main goals. The first examined the degree to which forgiveness and conflict tactics are related to each other, when both are reactions to a couple conflict instigated by a partner offence. We expected unforgiveness and avoidant/aggressive conflict strategies to overlap, but that benevolence and compromise will be less highly correlated. We also hypothesized that, due to their pro-relationship motivations (Karremans $\&$ Van Lange, 2004), benevolent partners would be more likely to adopt positive conflict tactics, such as compromising, in order to resume their relationship. Finally, we also hypothesized that benevolence and compromise would be inversely related to unforgiveness or avoidant/aggressive strategies (for the benevolence-unforgiveness association see for example: Fincham \& Beach, 2002; Fincham et al., 2004; Paleari et al., 2009; for the compromiseavoidance/aggression association see for example: Bertoni \& Bodenmann, 2006; Kurdek, 1994, 1995; Reese-Weber \& Bartle-Haring, 1998). 
The second goal of the study was to determine whether conflict strategies and forgiveness dimensions predict marital quality independently of each other, and whether they do so via effective arguing. This mediational hypothesis had never been previously tested. However, there is some evidence that partner reports of effective conflict management positively affect relationship quality over time (Kurdek, 1994) and research on couple conflict shows that adopting compromising conflict strategies, rather than avoidant and aggressive ones, is related to a more effective conflict resolution (Kerig, 1996) as well as to higher relational quality (Bertoni \& Bodenmann, 2006; Gottman \& Krokoff, 1989; Heavy, Layne \& Christensen, 1993; Kurdek, 1994). Similarly, forgiveness research suggests that forgiving the partner predicts stronger perceptions of effective arguing (Fincham et al., 2004) as well as greater relationship quality (for a review see Fincham et al., 2005). Consequently we hypothesized that individuals who forgive the partner and adopt compromising conflict tactics are more likely to think that they argue effectively as a couple and, consequently, to be satisfied with their romantic relationship. In the absence of prior research, we did not offer hypotheses about the unique effects of the predictors with the exception that, due to their conceptual overlap, aggressive and avoidant strategies do not predict effective arguing or relationship quality independently of unforgiveness.

In pursuing the above questions, this study also extends previous research by examining both cross-partner and within-partner effects in the same analysis (or both partners' cross-partner effects simultaneously). This means that the effects of each partner's forgiveness and conflict strategies upon the mediating variable (effective arguing) were simultaneously tested both when the mediating variable was measured in the same subject and when it was measured in his/her partner. This allowed us to examine the extent to which selfreported forgiveness and conflict tactics predict partner-reported perceptions of effective arguing and, indirectly, relationship quality, independently of partner-reported forgiveness and conflict tactics. In fact, one shortcoming of couple forgiveness research is that data relating to each partner have been analyzed separately, thereby failing to take into account their interdependence (Fincham, Hall \& Beach, 2005). Moreover, by including both partners' reports in the same analysis, we could test whether forgiveness and conflict strategies are associated across partners when they face analogous offending and conflicting episodes.

Specifically, existing research suggests that partners tend to reciprocate both positive and negative affect and behaviors (e.g., Gleason, Iida, Bolger \& Shrout, 2003; Gottman, 1979; Revenstorf, Vogel, Wegener, Halweg \& Schindler, 1979) as well as mutual forgiveness (Hoyt, Fincham, McCullough, Maio \& Davila, 2005). We therefore hypothesized that forgiveness and conflict tactics developed when being hurt by a significant conflict-promoting partner's offence are related to corresponding strategies their partners endorse in handling a similar situation. For example, we assumed that the more the subjects use aggressive strategies to manage couple conflicts originating from partner's offences the more their partners do the same in analogous circumstances. By including both partners' reports in the same analysis, we can also determine whether forgiveness and conflict strategies interact across partners in predicting effective arguing and relationship quality. This objective is consistent with a large literature in which partners' conflict resolution behaviors operate in interaction with each other to affect relationship quality. For example, Christensen's (e.g., Christensen \& Heavy, 1990) research on the "demand-withdraw" pattern indicates that wives' demanding and complaining tactics affect marital satisfaction in concert with husbands' avoidance; similarly studies on "negative reciprocity" pattern (e.g., Epstein, Baucom \& Rankin, 1993; Gottman, 1998) show that reciprocating negative behavior of one's partner leads to greater relational distress. 


\section{Method}

\section{Participants}

Participants were drawn from 120 childless community couples taking part in a larger study on romantic relationships in Italy. Couples were recruited from economics, engineering, and psychology classes and comprised volunteers who were married or were cohabiting with a romantic partner or had been seriously engaged to a noncohabiting romantic partner for at least 6 months. Volunteers and their partners were personally contacted by the experimenters who gave them a packet of questionnaires and both oral and written instructions for their compilation. No subject was rewarded or paid for his participation. Ninety two eligible couples returned completed questionnaires (56 were engaged, 22 married, and 14 cohabiting). ${ }^{1}$

The modal partner, whether male or female, was from Northern Italy (73.3\% of males and 69.6\% of females), had a mean age in the late 20s (males: $\mathrm{M}=29.5, \mathrm{SD}=5.15$; females: $\mathrm{M}=26.9, \mathrm{SD}=$ 3.83), had been involved in the reported romantic relationship an average of 4.5 years $(\mathrm{SD}=2.71)$, worked full-time, part-time, or occasionally $(89 \%$ of males and $60.4 \%$ of females), and reported an average net income of 500-1500 Euro (81.8\% of males and $68.5 \%$ of females). Most participants were Catholic (84.6\% of males and $95.7 \%$ of females) and considered themselves slightly or moderately religious $\left(60.8 \%\right.$ of males and $70.5 \%$ of females). ${ }^{2}$

\section{Procedure}

Participants received a packet of questionnaires to complete at home accompanied by separate return envelopes and a cover letter that instructed them

1 Married, cohabiting, and engaged partners did not significantly differ in the mean level of any of the variables investigated

2 Participants' religiousness was not significantly related to any of the variables investigated except for relationship quality and negative conflict resolution strategies which were found to covary weakly with religiousness in the male subsample only. Against expectations relationship quality was low and negative conflict resolution strategies more frequent when males were more religious $(\mathrm{r}=-0.26$ and .24 respectively). on what to do and thanked them for their participation. They were asked to complete the materials independently of their partner and to return them in separate envelopes before talking about the study. A similar procedure, asking subjects to complete questionnaires individually at home, was used in previous studies on forgiveness within couple relationships (e.g., Karremans et al., 2003; McCullough et al., 1998). As we computed the correlations of the male's reports with the female's reports across the investigated variables, we found that such correlations averaged $.36(\mathrm{SD}=0.51)$, indicating that the correspondence of reports between the two members of the couple was moderate.

\section{Measures}

Forgiveness and conflict strategies. Each participant was asked to think of the most serious offence by their partner which resulted in couple discord, a quarrel or a fight. One of the main goals of the present study was to investigate whether each partner's forgiveness for a conflict-promoting offence predicted effective arguing and relationship quality independently of the other partner's forgiveness as well as of conflict strategies such as aggression, avoidance, and compromise. Therefore, both members of the couple were invited to choose any episode in which they both felt hurt by partner behavior (rather than focus on the same episode in which they had contrasting perspectives of victim and perpetrator).

Participants then answered questions about the transgression and the conflict to which it gave rise, including the length of time since the offence and the consequent dispute, the seriousness of the offence and of the conflict $(1=$ not serious at all, $7=$ very serious), and how hurtful each was $(1=$ not hurtful at all; $7=$ very hurtful $)$. Both men and women recalled offences that occurred on average within the last year $(\mathrm{M}=10.87$ months prior to data collection, $\mathrm{SD}=14.18$ for men and $\mathrm{M}=11.49, \mathrm{SD}=16.92$ for women), and provoked an overt couple conflict within a month from their occurrence $(M=14.83$ days $(S D=53.99)$ for men and $\mathrm{M}=27.70$ ( $\mathrm{SD}=166.58)$ for women). Both men and women reported substantial and painful 
offenses which caused moderately serious conflicts (offence and conflict seriousness: $\mathrm{M}=3.64$ ( $\mathrm{SD}=$ $1.85)$ and $3.76(\mathrm{SD}=1.83)$ respectively for men, and $\mathrm{M}=4.08(\mathrm{SD}=1.69)$ and $3.97(\mathrm{SD}=1.75)$ for women; mean degree of hurt caused by the offense: $\mathrm{M}=4.07(\mathrm{SD}=1.86)$ for men and $4.92(\mathrm{DS}=1.71)$ for women). Compared to men, women reported more serious offenses $(\mathrm{t}(89)=2.244, \mathrm{p}=0.027)$ and higher degrees of hurt $(\mathrm{t}(90)=4.403, \mathrm{p}=0.000){ }^{3}$ Conversely, they did not differ from men in the conflict seriousness nor in the length of time that had passed since the offence and the consequent conflict occurred.

Participants were then invited to complete the Marital Offence-specific Forgiveness Scale (MOFS) and a Conflict strategy scale in order to evaluate their degree of forgiveness and the conflict resolution tactic used to deal with the dispute caused by the offence.

The MOFS (Paleari et al., 2009) is a 10-item psychometrically robust measure assessing marital forgiveness for a specific offence. In order to make the scale consistent with our goal of assessing forgiveness in romantic couples items were modified so that they referred to romantic partners in general rather than to spouses only. The scale comprises two dimensions: Benevolence, which consists of 4 items depicting benign and conciliatory reactions (e.g., "Since my partner behaved that way, I have done my best to resume our relationship", "I forgave her/him completely, thoroughly"), and Unforgiveness, which consists of 6 items assessing withdrawing and revengeful reactions (e.g., "Because of what happened, I find it difficult to act warmly toward her/him", "I still hold some grudge against my wife", "I feel like behaving towards my partner the same way she/he did to me"). Subjects were asked to rate their agreement with each of the 10 items on a 6 -point scale $(1=$ strongly disagree; $6=$ strongly agree). Except for women's Benevolence, in the current study the two subscales had an adequate internal consistency in both men $(\alpha=0.70$

3 Two subjects did not answered to questions concerning the transgression features; yet all subjects answered to the scales entered in the mediational model. and 0.76 for Benevolence and Unforgiveness respectively) and women ( $\alpha=0.62$ and 0.72 for Benevolence and Unforgiveness respectively). For each subscale, scores were averaged across items so that higher scores indicate higher benevolence (men: $\mathrm{M}=4.48, \mathrm{SD}=1.09$; women: $\mathrm{M}=4.35: \mathrm{SD}=1.07$; $\mathrm{t}(91)=-0.962, n s)$ and higher unforgiveness (men: $\mathrm{M}=1.91 ; \mathrm{SD}=0.92$; women: $\mathrm{M}=1.88 ; \mathrm{SD}=0.82$; $\mathrm{t}(91)=-0.347, n s)$.

The Conflict strategy scale was adapted from an Italian version of the Honess Style of Disagreement Scale (Guglielmetti, Iafrate \& Lanz, 1997; Honess \& Charmann, 1992), which assess behavioral reactions to conflicts. The Italian version of the Honess Scale comprises 4 subscales: avoidance, compromise, aggression, and physical violence. In the present study, the physical violence subscale was not considered since previous pilot studies on young community couples had shown that the subscale yielded a very strongly skewed distribution for both partners. In order to assess conflict strategy used to manage the single conflict remembered, rather than couple conflict styles in general, each item of the scale was changed so that it made reference to the conflict remembered (for example "the more I talk the more wound up I become" was changed to "the more I talk about what happened the more wound up I become"). Participants were then asked to rate their agreement with each of the 10 modified items on a 6-point scale (ranging from $1=$ strongly disagree to $6=$ strongly agree). A confirmatory factor analysis using structural equation modeling was conducted in order to ensure that the items reflected the same three correlated dimensions underlying the unmodified version of the scale. When the10 items were used as indicators of 3 correlated dimensions a good fit was found between the model and the obtained data for both men $\left(\chi^{2}(31)=38.76\right.$, $\mathrm{p}=0.16$; CFI $=0.969$; RMSEA $=0.052)$ and women $\left(\chi^{2}(31)=48.29, p=0.02 ; \mathrm{CFI}=0.913\right.$, RM$\mathrm{SEA}=0.078)$. Yet, the very high association between avoidance and aggression dimensions $(\mathrm{r}=0.97$ and 0.99 for men and women respectively) suggested that a more parsimonious two-factor solution could fit the data equally well. When a two-factor model, in which the association between attacking 
and avoidant behaviors was constrained to be one (thereby positing a single factor), was examined, an equally good fit of data was obtained for both men $\left(\chi^{2}(32)=38.94, p=0.19\right.$; CFI $=0.973$; RM$\mathrm{SEA}=0.049)$ and women $\left(\chi^{2}(32)=48.29, \mathrm{p}=0.03\right.$; $\mathrm{CFI}=0.918$; RMSEA $=0.075) .{ }^{4}$ Consequently, because of its parsimony, the two-factor solution was preferred to the three-factor one (Bollen, 1980). One factor comprised 6 items expressing the idea of attacking or avoidant behaviors (e.g., "I say or do something to hurt my partner's feelings" "I try to avoid talking about it"), while the second factor comprised 4 items expressing compromise (e.g., "I try to reason with my partner about what happened"). The two factors, respectively called Avoidance-aggression and Compromise, had an adequate internal consistency in both men $(\alpha=$ 0.80 and 0.69 respectively) and women $(\alpha=0.73$ and 0.74 respectively). Scores were averaged across items for each factor so that higher scores indicated a more avoidant and aggressive conflict strategy (men: $\mathrm{M}=2.38, \mathrm{SD}=1.07$; women: $\mathrm{M}=2.26$ : $\mathrm{SD}=0.97 ; \mathrm{t}(91)=-1.067, n s)$ and a more compromising one (men: $\mathrm{M}=4.58 ; \mathrm{SD}=0.98$; women: $\mathrm{M}=4.91 ; \mathrm{SD}=0.97 ; \mathrm{t}(91)=-2.804, \mathrm{p}=0.006)$.

Perceived effective arguing. Perceived effective arguing was assessed using the Ineffective Arguing Inventory (IAI, Kurdek, 1994) and scoring it so that high scores reflected effective conflict resolution. The IAI is based on descriptions of ineffective arguing found in marital research, such as fighting over repetitive issues, knowing how an argument is going to end even before it is over, ending the argument without resolving the issue at hand, and ending the argument with neither the partners feeling that they have been given a fair hearing (Markman, 1987; Snyder, 1981). It comprises 8 items measuring each partner's view of how effectively the respondent and his or her partner handle arguments as a couple (e.g., "Our arguments are left hanging and unresolved"). For each item, partners were asked to rate their agreement on a 5-point

4 In all the models tested we allowed the covariance of the measurement errors of two items to be estimated in order to improve the model fit. scale $(1=$ strongly disagree; $5=$ strongly agree $)$. The internal consistency for this scale was high (alpha coefficients were .81 and .80 for men and women respectively). Scores were averaged across items so that higher scores indicate a higher perceived effective arguing (men: $\mathrm{M}=4.91, \mathrm{SD}=0.72$; women: $\mathrm{M}=4.93: \mathrm{SD}=0.76 ; \mathrm{t}(91)=-0.212, n s)$.

Relationship quality. Relationship quality was measured using an adapted form of the Quality of Marriage Index (QMI, Norton, 1983). The QMI is a six-item inventory which assesses marital quality using broadly worded, global items (e.g., "We have a good marriage"). In the present study we replaced the words "marriage" and "spouse" with "relationship" and "partner" in order to assess relationship quality within the romantic relationships investigated. Similar to the original QMI, respondents indicated their degree of agreement with each of five items on a 7-point Likert-type scale $(1=$ very strong disagreement, $7=$ very strong agreement) and with one item ("indicate the degree of happiness, everything considered, in your relationship") on a 10-point Likert-type scale ( $1=$ very unhappy, $10=$ perfectly happy). Since the data were positively skewed, the following transformation recommended by Norton (1983) was used: first, the distribution of the QMI (i.e. summed z scores from the six items) was stratified into 5\% intervals; second the variance across the intervals was added to each QMI score; third each score obtained was raised to the third power and divided by 1000 . The algorithm basically indicates that data are cubed to obtain a linear model. Higher scores correspond to higher levels of relationship quality (men: $\mathrm{M}=$ 33.98; $\mathrm{SD}=12.61$; women: $\mathrm{M}=33.87$; $\mathrm{SD}=12.16$; $\mathrm{t}(91)=-0.087, \mathrm{~ns})$. In the present study, the QMI had high internal consistency (alpha coefficients were .94 and .93 for men and women respectively).

\section{Data analysis strategy}

We first examined the associations between forgiveness dimensions (Benevolence and Unforgiveness) and conflict strategies (Avoidance-aggression and Compromise) using Pearson product moment correlations. The relation between the 
constructs was further examined using confirmatory factor analysis. Specifically, we compared a four-factor solution, in which the items of Benevolence, Unforgiveness, Avoidance-aggression, and Compromise were allowed to load on four separate interrelated factors, to a three-factor solution, in which the association between Unforgiveness and Avoidance-aggression was constrained to be one, as well as to a two-factor solution, in which both the association between Unforgiveness and Avoidance-aggression and the association between Benevolence and Compromise were constrained to be one. According to Bollen (1980), the four-, three-, and two-factor solutions can be compared by interpreting the change in $\chi^{2}$ (per change in $\mathrm{df})$ as a $\chi^{2}$ statistic. The model with significantly better fit can be retained as the best description of the observed data. If models are not significantly different, then the law of parsimony suggests that the model with fewer paths is a superior description of the structural relations among the constructs in the model. Goodness of model fit was evaluated through the chi-square statistic (Jöreskog \& Sörbom, 1984), the Comparative Fit Index (CFI) (Bentler, 1990), and the Root Mean Square Error of Approximation (RMSEA) (Bentler, 1995). A significant chi-square statistic may suggest that the hypothesized model does not adequately fit the observed data. However, because the chi-square statistic is sensitive to sample size, we also used alternative fit indexes, the CFI and the RMSEA, which are not adversely affected by sample size. The CFI is usually considered to show a good fit when it is .90 or higher (Bentler, 1995), while a RMSEA value of .08 or lower has been suggested to reflect a reasonable fit (Browne \& Cudeck, 1993). In order to improve the ratio of the sample size to the size of the covariance matrix, we used a partial aggregation approach, that is we grouped the items of each construct (i.e. Benevolence, Unforgiveness, Avoidance-aggression, and Compromise) into subsets of 2 items that appeared to tap the same facet of the construct, as suggested by Bagozzi and Heatherton (1994).

Second, we examined bivariate and partial correlations among the variables investigated in order to verify that associations among variables were in the expected direction. In the event that any variable had no significant associations with the remaining ones, we decided to drop the variable from the hypothesized mediational model so as to increase statistical power.

Third, we tested the mediational model hypothesized using measured variables rather than latent variables owing to our sample size. ${ }^{5}$ Specifically, we first estimated the hypothesized model using EQS version 5 (Bentler, 1995) and progressively improved it by examining Wald and Lagrange statistics. The Wald test assesses whether sets of parameters specified as free in the model could in fact be simultaneously set to zero without significant loss in model fit. Conversely, the Lagrange Multiplier test assesses whether the addition of certain paths or parameters not present in the model would result in a significant increase in model fit (Bentler, 1986). The statistical significance of indirect (or mediational) effects was tested via EQS in which the Sobel method (1987) is implemented. In order to test for gender differences, the paths from forgiveness and conflict strategies to effective arguing and from effective arguing to relationship quality were further constrained as equal across partners. The Lagrange multiplier (LM) test was then used to determine if significant amounts of variance were explained if the constraints were released.

We also tested a competing model in which the paths between perceived conflict resolution efficacy and relationship quality were reversed for both partners. In contrast to the proposed model, according to which forgiveness and conflict resolution strategies uniquely predict relationship quality via perceived effective arguing, the alternative model specified that forgiveness and conflict strategies

5 Even though the ratio of parameters estimated to subjects was 3.8 in the models tested, that is lower than the 5 one recommended by some authors (e.g. Bentler \& Chou, 1987), recent work (MacCallum, Browne \& Sugawara, 1999) on the question of sample size in SEM has shown that it is impossible to derive a minimum ratio that is appropriate in all situations, rather the minimum sample size is highly dependent on several characteristics, including the average communality of measured variables. When communalities are high $(>.6)$, as they are in the present study, sample sizes of about 100 subjects are often adequate. 
predicted relationship quality which, in turn, influenced perceived effective arguing. Furthermore, in order to verify that the constructs investigated do not merely reflect relationship quality, we tested a CFA model in which male and female observed variables loaded onto two covarying factors (i.e. men and women's relationship quality); the variables were allowed to covary within gender. The appropriateness of the two alternative models was compared with that of the hypothesized one by evaluating the Akaike Information Criteria (AIC, Akaike, 1973) for the two solutions: the model with the lowest AIC is preferable.

Finally, possible across-partner interactions between forgiveness and conflict strategies in predicting effective arguing and relationship quality were examined. Specifically, following Aiken and West's (1991) recommendations, regression analyses were conducted by entering both partners' centered forgiveness and conflicts tactics scores as well as the interactions of women-centered tactics with men-centered tactics (e.g., women benevolence $\mathrm{x}$ men benevolence, women benevolence $\mathrm{x}$ men compromise,...) as predictors of either women and men's effective arguing or relationship quality. Because the ratio of predictor variables to subjects was less than optimal, we focused only on those interactions which might be useful to explain, in terms of moderating effects, the lack of significant relations between any predictor and the outcome variables.

\section{Results}

\section{Relations between forgiveness dimensions and conflict strategies}

Bivariate correlations indicate that the association between the Avoidance-aggression conflict strategy and the Unforgiveness dimension of forgiveness was strong $(r=0.71$ and .67 in men and women respectively), while the association between Forgiveness and Compromise was moderate $(\mathrm{r}=0.55$ and .57 in men and women respectively). Confirmatory factor analysis showed that a four-factor model in which Benevolence, Unforgiveness, Avoidance-aggression and Compromise loaded on four distinct covarying factors did not fit the data better than a more parsimonious three-factor model in which Unforgiveness and Avoidanceaggression were forced to load on the same factor, in both men (four-factor model: $\chi^{2}(29)=42.11$, $\mathrm{p}=0.05$; CFI $=0.964$; RMSEA $=0.070$; three-factor model: $\chi^{2}(30)=45.46, p=0.04 ; C F I=0.957$; RMSEA $\left.=0.075 ; \Delta \chi^{2}(1)=3.35, n s\right)$ and women (four-factor model: $\chi^{2}(29)=48.56, p=0.01$; $\mathrm{CFI}=0.939$; RMSEA $=0.086$; three-factor model: $\chi^{2}(30)=51.59, \mathrm{p}=0.01$; CFI $=0.932$; RM$\left.\mathrm{SEA}=0.089 ; \Delta \chi^{2}(1)=3.03, n s\right)$. Moreover, the three-factor model provided a significantly better fit than a two-factor model in which Benevolence and Compromise were forced to load on the same factor, in both men (two-factor model: $\chi^{2}(31)=54.46, p=0.01$; CFI $=0.935$; RM$\left.\mathrm{SEA}=0.091 ; \Delta \chi^{2}(1)=9.00, \mathrm{p}<.01\right)$ and women (two-factor model: $\chi^{2}(31)=58.35, \mathrm{p}<.01$; $\mathrm{CFI}=0.914 ; \mathrm{RMSEA}=0.098 ; \Delta \chi^{2}(1)=6.76$, $\mathrm{p}<.01)$. Thus, consistent with our assumptions, an overlap was found between Avoidance-aggression and Unforgiveness, but not between Benevolence and Compromise. Accordingly, Avoidance-aggression and Unforgiveness were averaged to form one index labelled Avoidant-aggressive unforgiveness; higher scores on the index correspond to higher levels of unforgiving, avoidant and aggressive behaviors (men: $\mathrm{M}=33.98$; $\mathrm{SD}=12.61$; women: $\mathrm{M}=33.87 ; \mathrm{SD}=12.16)$.

\section{Correlations among the variables investigated}

Correlations among the variables investigated (see Table 1) indicate that most of them were associated with each other in the expected manner.

Replicating prior findings (e.g., Fincham et al., 2004; Kurdek, 1994), each partner's effective arguing was related to self-reported and partnerreported relationship quality (r's ranged from .44 to .64). Also, consistent with past research (e.g., Fincham et al., 2004), each partner's avoidant-aggressive unforgiveness was significantly correlated 
TABLE 1

Correlations among study variables $(n=92)$

\begin{tabular}{|c|c|c|c|c|c|c|c|c|c|}
\hline & 2 & 3 & 4 & 5 & 6 & 7 & 8 & 9 & 10 \\
\hline 1. M benevolence & $.055 * * *$ & $-.049 * * *$ & $.046 * * *$ & $.052 * * *$ & $.021 *$ & $.022 *$ & -.008 & $.021 *$ & $.028 * *$ \\
\hline 2. $M$ compromise & - & $-.033 * *$ & $.029 * *$ & $.031 * *$ & .007 & $.031 * *$ & -.014 & $.031 * *$ & $.030 * *$ \\
\hline $\begin{array}{l}\text { 3. } \mathrm{M} \text { avoidant-aggres- } \\
\text { sive unforgiveness }\end{array}$ & & - & $-.072 * * *$ & $-.057 * * *$ & -.012 & .001 & $.041 * * *$ & $-.048 * * *$ & $.050 * * *$ \\
\hline 4. $M$ effective arguing & & & - & $.064 * * *$ & .020 & .007 & $-.042 * * *$ & $.048 * * *$ & $-.052 * * *$ \\
\hline 5. M relationship quality & & & & - & .013 & .001 & $-.036 * * *$ & $.044 * * *$ & $.056 * * *$ \\
\hline 6. W benevolence & & & & & - & $.057 * * *$ & $-.035 * *$ & .020 & $.025 *$ \\
\hline 7. W compromise & & & & & & - & -.018 & .014 & .012 \\
\hline $\begin{array}{l}\text { 8. W avoidant-aggres- } \\
\text { sive unforgiveness }\end{array}$ & & & & & & & - & $-.053 * * *$ & $-.050 * * *$ \\
\hline 9. W effective arguing & & & & & & & & - & $.055 * * *$ \\
\hline $\begin{array}{l}\text { 10. W relationship } \\
\text { quality }\end{array}$ & & & & & & & & & - \\
\hline
\end{tabular}

NOTE: Cross-partner correlations are reported in italics. $M=$ men, $W=$ women.

$* \mathrm{p}<.05, * * \mathrm{p}<.01, * * * \mathrm{p}<.001$

Source: own work

with self-reported and partner-reported effective arguing (r's ranged from -.42 to -.72) as well as with self-reported and partner-reported relationship quality (r's ranged from -.36 to -.57). For husbands, benevolence and compromise also related to both partners' effective arguing ( $r$ 's ranged from .21 to .46) and both partners' relationship quality (r's ranged from .28 to .52). However, the correlations involving women's benevolence and compromise suggested some modifications to our original model as these variables did not correlate with either partners' effective arguing nor with their relationship quality (with the exception of a significant but weak correlation between women's benevolence and own relationship quality, $r=0.25)$. Partial correlations confirmed that, after controlling for the remaining conflict resolution strategies, women's benevolence and compromise were not significantly correlated with effective arguing and relationship quality in either men or women. Consequently, these two variables were not included in the mediational model tested so as to increase its power. The model tested (in which women's benevolence and compromise were omitted) is shown in Figure 1.

\section{Testing the mediational model}

The model specified in Figure 1 provided a poor fit to the data $(\chi 2(12)=38.58, p=0.000$; CFI $=$ 0.910; $\mathrm{RMSEA}=0.156 ; \mathrm{AIC}=14.585)$. The Wald test suggested removal of three paths: the one from men's benevolence to women's effective arguing, the path from men's compromise to men's effective arguing, and the correlation between men's and women's effective arguing. Conversely, the Lagrange Multipler test suggested the addition of three paths: from men's benevolence to men's relationship quality and the paths from men's and women's avoidant-aggressive unforgiveness to women's relationship quality. When these changes were made, the model provided a good fit to 


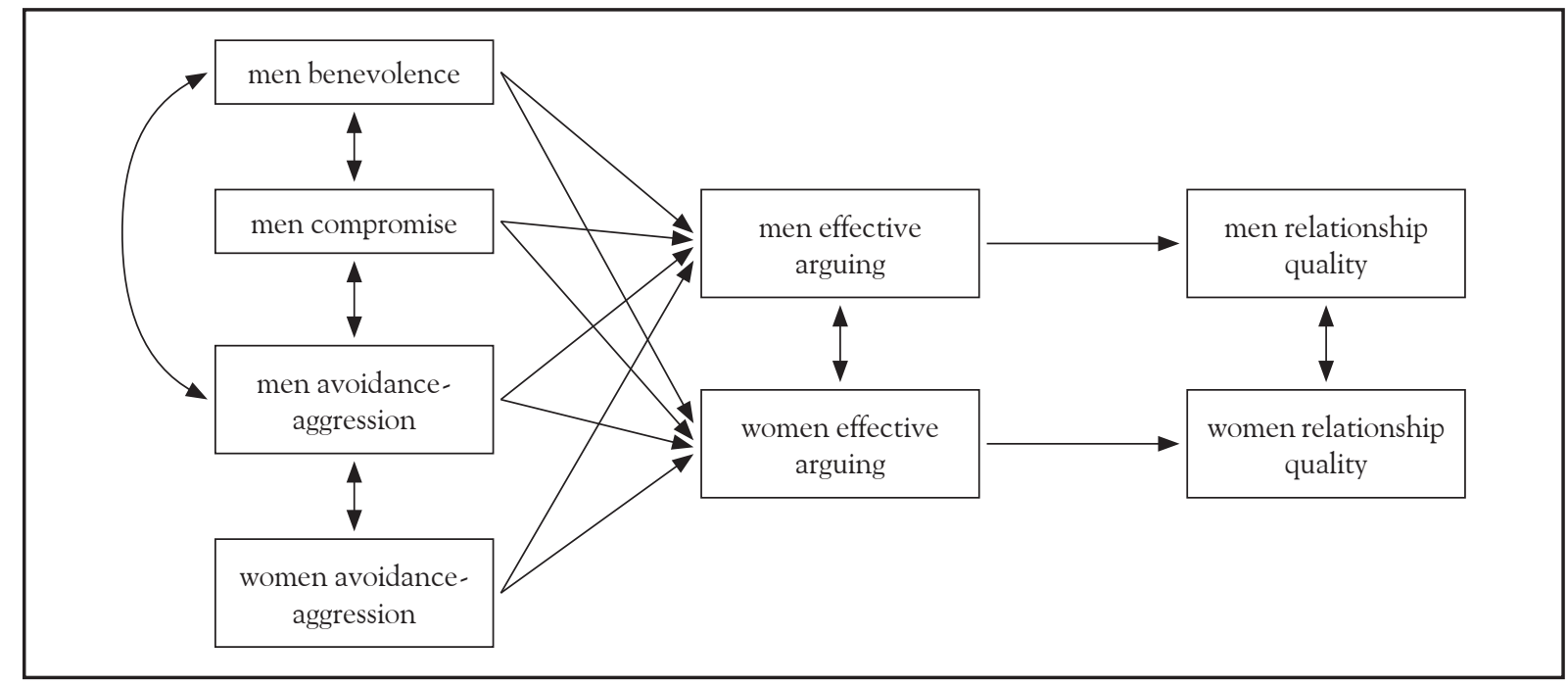

FiguRE 1

Hypothesized model of relations among men's and women's forgiveness, conflict strategies, effective arguing, and relationship quality.

Note: Women's benevolence and compromise were omitted because they were not related with effective arguing and relationship quality in either men or women.

Source: own work

the data $\left(\chi^{2}(12)=16.68, p=0.162 ; C F I=0.984\right.$; $\mathrm{RMSEA}=0.065 ; \mathrm{AIC}=-7.324)$ and accounted for a good amount of variance in relationship quality $\left(\mathrm{R}^{2}=.44\right.$ and .38 for men and women respectively). Parameter estimates for this final model are presented in Figure 2.

The parameter estimates indicate that each partner's effective arguing was best predicted by his own/her own avoidant-aggressive unforgiveness in that the more subjects used this tactic, the less likely they were to report handling conflicts in a successful and adaptive way ( $\beta=-0.56$ and -.40 for men and women respectively). After controlling for the remaining exogenous variables, compromise was not linked to self-reported effective arguing in either men or women and benevolence was weakly related to self-reported effective arguing in men only $(\beta=0.18)$.

Furthermore, each subject's effective arguing was concurrently predicted, although weakly, by conflict resolution strategies adopted by the partner. In particular, men's effective arguing was related to their partner's avoidant-aggressive unforgiveness ( $\beta=-0.18)$, whereas women's effective arguing was significantly predicted by both their partner's compromising $(\beta=0.18)$ and avoidantaggressive unforgiving strategy $(\beta=-0.25)$. Thus, women judged their couple conflicts to have been positively handled as long as their partner had not been avoidant-aggressive unforgiving, but compromising. Similarly, men thought that relational conflicts had been effectively handled to the extent to which their wives had not used an avoidantaggressive unforgiving tactic.

Consistent with our hypotheses, both men and women's effective arguing predicted their own ratings of relationship quality $(\beta=0.49$ and $\beta=0.28$ respectively). Also, all the indirect effects included in the model - namely the indirect effects of men's benevolence $(\beta=0.09)$ and men and women's avoidant-aggressive unforgiveness $(\beta=-0.28$ and -.09 respectively) upon men's relationship quality and the indirect effects of men's compromise $(\beta$ $=0.05)$ and men and women's avoidant-aggressive unforgiveness ( $\beta=-0.07$ and -.011) upon women's relationship quality-were statistically significant. Consequently, as we assumed, forgiveness and conflict strategies predicted both partners' relationship 


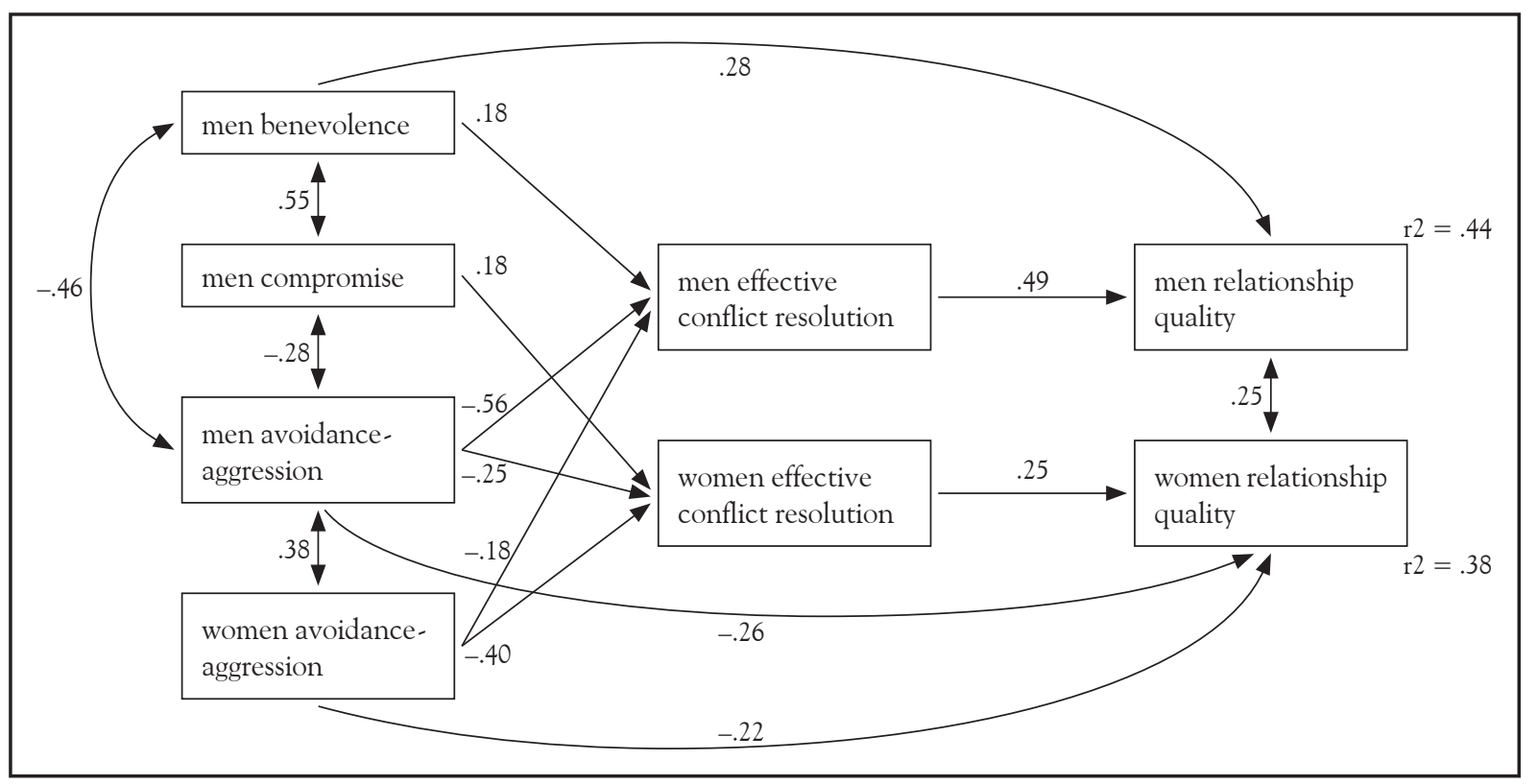

Figure 2

Path analyses of obtained relations among men's and women's forgiveness, conflict strategies, effective arguing, and relationship quality.

Note: All coefficients are significant beyond the $\mathrm{p}<0.05$ level.

Source: own work

quality through the mediation of self-reported effective arguing. Contrary to our predictions, however, this mediation was only partial. In fact, independent of the remaining exogenous variables, both men's benevolence and women's avoidantaggressive unforgiveness directly predicted their own ratings of relationship quality ( $\beta=0.28$ and $\beta=-0.22$ respectively); moreover, men's avoidant-aggressive unforgiveness directly predicted partner-reported relationship quality $(\beta=-0.26)$.

When overall effects (i.e. direct plus indirect ones) ware considered, the exogenous variables best predicting self-report relationship quality were benevolence for men (overall effect: $\beta=0.37$ ) and avoidant-aggressive unforgiveness for women (overall effect: $\beta=-0.34$ ). This means that, women expressed higher relationship quality when they had not adopted an avoidant-aggressive unforgiving strategy in response to a conflict originating from a partner's offence, whereas for men relationship quality was judged to be higher when they had been benevolent toward the offending partner.
Cross-partner analyses indicated that conflict resolution tactics adopted had significant effects on partner-reported marital quality. In particular, not adopting an avoidant-aggressive unforgiving tactic by men was positively related, both directly and indirectly, to their partner's satisfaction (overall effect: $\beta=-0.34$ ). Significant indirect effects upon partner-reported relationship quality, although much weaker, were also found for men's compromise $(\beta=0.05)$ and women's avoidant-aggressive unforgiveness $(\beta=-0.09)$.

When gender differences were tested, by constraining significant paths as equal across partners, all the three pair of paths constrained-namely the within-partner paths from avoidant-aggressive unforgiveness to effective arguing (men's $\beta=-0.46$, women's $\beta=-0.40$ ), the within-partner paths from effective arguing to relationship quality (men's $\beta$ $=0.49$, women's $\beta=0.28$ ), and the between-partner paths from avoidant-aggressive unforgiveness to effective arguing (men's $\beta=-0.25$, women's $\beta$ $=-0.18)$ - were found to be significantly stronger 
in males than in females. This means that, compared to women, men's avoidant-aggressive unforgiveness had stronger effects on effective arguing and, indirectly, on relationship quality, both within and across partners.

Finally, we compared the models discussed thus far to the alternative models previously described, in which (a) the paths linking effective arguing to relationship quality were reversed or (b) the variables investigated were considered as indicators of a relationship quality dimension. The first alternative model provided a worse fitting description of the structural relations among the variables investigated when compared to both the hypothesized and final model $\left(\chi^{2}(12)=58.36, p=0.000\right.$; $\mathrm{CFI}=0.844 ; \mathrm{RMSEA}=0.206 ; \mathrm{AIC}=34.356)$. The second alternative model was also rejected as it provided a worse fitting description of the structural relations among the variables investigated when compared to the final model $\left(\chi^{2}(19)=\right.$ 42.49, $\mathrm{p}=0.001 ; \mathrm{CFI}=0.921$; $\mathrm{RMSEA}=0.117$; $\mathrm{AIC}=4.478)$.

\section{Moderational analyses}

Contrary to our predictions, we found that women's constructive responses to conflict (benevolence and compromise) were unrelated to the two partners' perceived effective arguing and relationship quality. In order to interpret this unexpected result, we tested a moderational hypothesis according to which the non significant paths between women's benevolent and compromising responses and the outcome variables investigated might be predicted by the conflict strategies endorsed by the male partner in analogous offending and conflicting situations. As previously noted, this hypothesis is consistent with a large literature in which partners' conflict resolution behaviors operate in interaction with each other to affect relationship quality. Even though the results must be regarded as tentative because of the low ratio of predictor variables to subjects, we found that the, when women's effective arguing was the criterion, the women benevolence $\mathrm{x}$ men avoidant-aggressive unforgiveness interaction $(\beta=-0.27, p=0.062)$ and the women compromise $\mathrm{x}$ men benevolence interaction $(\beta=0.53, p=0.023)$ approached and reached statistical significance, respectively. Thus, women's benevolence in response to a partner's conflict-promoting offence positively predicts their own perception of effective arguing when men's level of avoidant-aggressive unforgiveness for a similar offending and conflicting episode is low (simple slope $=0.21, p=0.054)$ whereas it has negative effects when men's level of avoidantaggressive unforgiveness is high (simple slope $=$ $-0.20, p=0.057)$. Moreover, women's compromise negatively predicts their own perception of effective arguing when men's level of benevolence is low (simple slope $=-0.35, \mathrm{p}=0.041$ ), whereas it has no significant effect when men's level of benevolence is high (simple slope $=0.19, p=0.175$ ).

Comparable results emerged for the effects of women's benevolence and compromise on selfreported and partner-reported relationship quality. That is, women's benevolence and compromise did not significantly correlate with their relationship quality, probably because of the moderating effects of men's conflict strategies. Thus, similar to the results for effective arguing, we found that the links from women's benevolence and compromise to their appraisals of relationship quality are respectively moderated by their partner's avoidantaggressive unforgiving $(\beta=-0.30, p=0.034)$ and benevolent $(\beta=0.45, p=0.046)$ conflict tactics. In particular, women's relationship quality is positively predicted by their benevolence in response to a partner's conflict-promoting offence when men show little avoidant-aggressive unforgiveness in analogous offending and conflicting situations (simple slope $=5.62, \mathrm{p}=0.012$ ) and is negatively predicted by their compromise strategy when men exhibit low levels of benevolence (simple slope $=-5.67, p=0.031$ ). Similar results also emerged for men's relationship quality which was significantly affected by the women benevolence $\mathrm{x}$ men avoidant-aggressive unforgiveness interaction $(\beta=-0.37, p=0.005)$ and the women compromise $x$ men benevolence interaction $(\beta=0.69$, $\mathrm{p}=0.001$ ). Specifically, women's benevolence positively predicts men's relationship quality when 
men's level of avoidant-aggressive unforgiveness is low (simple slope $=2.39, \mathrm{p}=0.020$ ) whereas it has negative effects when men's level of avoidant-aggressive unforgiveness is high (simple slope $=-4.16$, $\mathrm{p}=0.027$ ). Moreover, women's compromise negatively predicts men's relationship quality when men's level of benevolence is low (simple slope $=-3.36$, $\mathrm{p}=0.001$ ), whereas it has no significant effect when men's level of benevolence is high (simple slope $=$ $3.59, \mathrm{p}=0.085$ ).

\section{Discussion}

Although forgiveness and couple conflict have been extensively investigated (for reviews see, Booth, Crouter \& Clements, 2001; Fincham \& Beach, 1999; McCullough et al., 2000; Worthington, 2005), they have been rarely examined together, especially in the context of close relationships (for an exception see Fincham, et al., 2004). Hence, even though forgiveness is likely one of the strategies couples may use to cope with conflicts entailing a personal offence, the relation between forgiveness and the aggressive, avoidant, and compromising tactics typically investigated in the couple conflict literature (see Veroff et al., 1997) and the unique effects of each on conflict resolution and relationship quality are not clear. The major purposes of the present study were therefore to analyze forgiveness dimensions (benevolence and unforgiveness) and aggressive, avoidant, and compromising conflict strategies in order to evaluate their reciprocal relations as well as their unique role in predicting perceived effective arguing and relationship quality.

In view of both theoretical considerations and empirical operalizations of the constructs (e.g., Enright et al., 1998; Fincham, 2000; Klein \& Johnson, 1997; McCullough et al., 1997, 2000), we assumed that, when they are considered in relation to conflicts originating from significant partner's offences, unforgiveness and avoidant-aggressive conflict strategies overlap owing to their shared behavioral component; conversely, we hypothesized that, because of its lesser behavioral component and more predominant intrapersonal component, benevolence is distinct and not confounded with compromise, even though a correlation between the two is expected. Secondly, we postulated that, despite their mutual relations, forgiveness dimensions as well as aggressive, avoidant, and compromising conflict strategies predict marital quality via perceived effective resolution. In fact there is evidence to show that marital quality is significantly affected by partners' perceptions of effective conflict resolution (e.g., Fincham et al., 2000; Kurdek, 1994) which, in turn, is predicted by both forgiveness (Fincham et al., 2004) and conflict management strategies (e.g., Kluwer, Heesink \& Van de Vliert, 1997). In order to take into account the interdependence between the two partners' data, the mediational hypothesis was simultaneously tested within-partners and across-partners by estimating a mediational model in which each partner's forgiveness and conflict strategies predicted both partners' perceived effective arguing that, in turn, predicted their own relationship quality.

The results obtained indicate that, consistent with our assumptions, unforgiveness and avoidance/aggressive conflict tactics largely overlap when both are considered as responses to conflicts originating form partner's offences. The overlap does not necessarily mean that forgiveness and avoidant-aggressive conflict strategies are one and the same, but simply that in specific circumstances, namely when conflicts are instigated by offences, the negative dimension of forgiveness (unforgiveness) and the avoidant-aggressive conflict strategies are somewhat confounded. This probably happens because both the constructs are mostly conceptualized and empirically assessed in terms of similar behavioral responses (see Fincham, 2000). Conversely, the positive dimension of forgiveness or benevolence was not found to overlap substantially with compromise, the constructive conflict tactic here investigated, but correlated only moderately with it. This result is consistent with our assumptions postulating that the behavioral component of forgiveness is less evident in its benevolence dimension. 
Also, consistent with the hypothesized mediational model, our findings indicate that forgiveness as well as conflict strategies play a significant role in predicting relationship quality via effective arguing, both within and across partners. Stated differently, support emerged for the hypothesis that both partners' effective arguing mediates the relation between each partner's conflict strategies and their relationship quality.

Consistent with previous research (e.g., Fincham et al., 2000; Kurdek, 1994), we found that men's and women's reports of effective arguing predicted their own relationship quality, even when controlling for forgiveness and conflict strategies endorsed in reaction to conflicts instigated by partner offences. Moreover, men's and women's reports of effective arguing were predicted by both their own and their partner's way of managing offending and conflicting episodes in their romantic relationship. More specifically, men's and women's avoidant-aggressive unforgiveness, which captures the negative dimension of forgiveness as well as avoidant-aggressive conflict strategies, was found to be strongly related to self-reported effective arguing and more weakly, although significantly, to partner-reported effective arguing. These data are consistent with Fincham et al.'s (2004) finding that husband unforgiveness predicts wives' report of destructive arguing, but not with the one showing that women's unforgiveness is unrelated to men's reports of ineffective arguing. The present cross-partner effects for both men and women's unforgiveness may be explained by some important methodological differences between the two studies. For example, the unforgiveness items administered in the present study were different from the Fincham et al. (2004) ones and merged with items assessing aggressive and avoidant conflict strategies. Also, couples participating in the present research were either dating, cohabiting or married couples, while Fincham et al.'s studies considered married couples only.

The present results extend Fincham et al.'s previous findings by demonstrating that each partner's unforgiveness (captured by the avoidant-aggressive unforgiveness indicators) showed cross-partner links with effective arguing even when withinpartner effects were simultaneously estimated. This result suggests that each partner's unforgiveness has unique consequences on both partners' perception of successful conflict resolution. In other words, men and women who respond to conflicts originating from partner's offences by being avoidant and vengeful are likely to undermine both their own and their partner's confidence that they can successfully resolve their conflicts. Thus, as assumed by interdependence theory (Kelley, 1983; Kelly \& Thibaut, 1978), individuals involved in close relationship conflicts appear to have reciprocal, strong, and diverse impacts on each other.

It is worth noting, however, that even though the present findings reveal that the negative dimension of forgiveness plays a role in predicting perceived effective arguing, its role is not independent of the one exerted by avoidant and aggressive conflict strategies with which unforgiveness overlaps. Thus, the finding that men's and women's avoidant-aggressive unforgiveness predict self-reported and partner-reported effective arguing also supports findings from the couple conflict literature that adopting more destructive and avoidant conflict strategies is related to more ineffective conflict resolution (Kerig, 1996).

Compared to aggressive, avoidant and unforgiving responses, compromising and benevolent ones had an overall weaker role in predicting selfreported and partner-reported effective arguing. This result mirrors those found in a number of studies in which negative attitudes and behaviors have shown a greater impact on marital relationships than positive ones (Amato \& Rogers, 1997; Burman et al., 1992; Huston \& Vangelisti, 1991).

Moreover, when predicting effective arguing from constructive responses, different patterns of results emerged for men and women. Specifically, men's benevolence and compromise were weakly but significantly related to self-reported and partner-reported effective arguing, respectively. But women's benevolence and compromise were not significantly related to either self-reported or partner-reported effective arguing. These findings differ from Fincham et al.'s (2004) finding that 
wives' benevolence predicts husbands' report of constructive arguing. It is important to remember, however, that we improved on Fincham et al.'s studies by analyzing concurrently both partners' reports of conflict strategies and effective arguing. Consequently, the lack of a significant association between women's benevolence and partnerreported or self-reported perception of effective arguing in our study might be due to the potential moderating effects of conflict strategies adopted by the partner. Consistent with this view, moderational analyses revealed that women's benevolence in response to their partner's conflict-promoting offences was positively related to their perceptions of effective arguing as long as men showed little avoidance-aggression and unforgiveness in reaction to similar offending and conflicting episodes, but it was negatively related to effective arguing when men used avoidant-aggressive and unforgiving conflict tactics. Similarly, women's compromise is likely to worsen their appraisals of effective arguing as long as men's conflict strategies show little benevolence.

The moderational findings for relationship quality were comparable to the ones obtained for effective arguing. Specifically, women's appraisals of relationship quality were positively related to their own benevolent reactions to conflicts originating from partner's offences only if men showed low levels of avoidant-aggressive and unforgiving reactions in similar situations and women's appraisals of relationship quality were negatively related to their own compromise when men showed little benevolence. If we bear in mind that men and women assessed their own forgiveness and conflict strategies in relation to possibly different events (i.e. the most serious offence suffered by their partner from which couple conflict had ever originated), the above findings suggest that women's relational outcomes suffer when they report to have forgiven the partners' offences or to have been compromising for their partner, but their partners do not appear to have forgiven women's transgressions, thereby leading to a violation of the positive reciprocity norm. This norm is particularly strong in close relationships (Cotterell, Eisenberger \&
Speicher, 1992), and implies an obligation to repay favorable treatment (Gouldner, 1960) including forgiveness granted by the partner. Hoyt and colleagues (2005), for example, found some evidence of reciprocity in marital forgiving: husbands who were willing to forgive their wives were usually forgiven by them, and vice versa. Since positive reciprocity strengths pro-relationship motivation and behaviors as well as a long-term orientation, its violation by men's failure to forgive their forgiving and compromising female partners is likely to be a serious threat to satisfying couple relationships (e.g., Karremans \& Van Lange, 2004)

Even though our results require replication using a larger and more heterogeneous sample, they highlight the importance of comprehensively examining couple conflict and forgiveness from a two-partner perspective. In fact, similar to other well-investigated conflict strategies (see for example women's demand, Heavy, Layne \& Christensen, 1993), women's benevolence and compromise best predicted effective arguing and relationship quality in interaction with the partner's conflict strategies. In contrast, men's constructive strategies predicted effective arguing and relationship quality mostly independently of the partner's conflict strategies; after controlling for women's conflict tactics, men's benevolence had both direct and mediated positive effects on self-reported relationship quality, while men's compromise predicted partner-reported relationship quality through the mediation of effective arguing only.

The present data suggest the existence of gender differences in the way appraisals of relationship quality and effective arguing are related to conflict strategies. While women's judgments were predicted by both their own and their male partner's constructive strategies (benevolence and compromise), men's appraisals were mainly predicted by their own constructive strategies. Correspondingly we found that destructive avoidant-aggressive and unforgiving strategies had much stronger overall cross-partner effects in men (5 significant crosspartner effects ranging from -.27 to .18) than in women ( 2 significant cross-partner effects ranging from -.18 to - .09 and significantly lower than the 
equivalent men's ones). We think that the gender related findings might reflect different levels of selfconstrual. According to Cross and Madson (1997), the social, institutional, and cultural environment of Western societies promotes development of a personal or independent self-construal in men and of an interdependent or relational self-construal in women (see also, Brewer \& Gardner, 1996; Markus \& Kitayama, 1991). Consequently, women are more likely than men to represent themselves as being connected with the partner, to attend to the partner's behaviors, and to be open to being affected by them. Therefore, women may be more sensitive than men to their partner's conflict strategies when evaluating the couple relationship.

Contrary to benevolence and compromise, avoidant-aggressive and unforgiving strategies were found to have negative cross-partner and within-partner effects on relationship quality in both men and women. The present findings are consistent with forgiveness research showing that, while benevolence enhanced positive relational outcomes, unforgiveness reduced them (Fincham \& Beach, 2002; Gordon \& Baucom, 2003; Paleari et al., 2005; Tsang et al., 2006). Also the findings are consonant with a large literature showing that negative conflict resolution strategies lead to lower couple satisfaction and increased relational distress, while positive conflict strategies forecast healthy relational outcomes (e.g., Julien, Markmann \& Lindahl, 1989; Kurdek, 1995; Noller, Feeney, Bonnell \& Callan, 1994).

Finally, as noted before, when the links tested are considered as a whole, good support emerged for the hypothesis that both partners' effective arguing mediates the relationship between conflict strategies and relationship quality. Thus, partners using positive conflict tactics instead of negative ones are more satisfied with their relationships probably because they view the way conflict is managed more positively. However, contrary to our hypotheses, the mediating role of effective arguing was partial. For men relationship quality was directly predicted by their own benevolence, whereas for women relationship quality was directly predicted by both their own and their partner's avoidant-aggressive unforgiving tactics. Mediating variables other than the ones examined in the present study are likely to be important. For example, besides affecting perception of effective conflict resolution, forgiveness helps the victim to regain a more positive and balanced view of the partner and of the relationship, which fosters marital adjustment (e.g. Gordon \& Baucom, 2003). Also, forgiving people tend to exhibit stronger prorelationship motivations and behaviors, like higher levels of willingness to sacrifice and to cooperate, which in turn help to maintain well-functioning interpersonal relationships (Karremans \& Van Lange, 2004). Finally, partners who can handle conflict more constructively, with more positive communication and less negative interactions, create an environment that allows for higher levels of self-disclosure which is a central aspect of intimacy (Cordova \& Dorian, 2004; Laurenceau, Barrett \& Rovine, 2005).

The findings of this study need to be viewed in the context of its limitations. First, the demographic characteristics of the sample, that is young well-educated romantic couples, living in Northern Italy, are probably not representative of the general Italian population and thus it is unclear how well our results will generalize. Further research is needed to replicate them using larger and more heterogeneous samples as well as to verify whether results are statistically invariant across the different types of couples (engaged, cohabiting, and married) we investigated. Second, because the low reliability of women's benevolence measure might have been responsible for its non-significant links with relational outcome variables, it will be important to check if similar results are obtained using more reliable benevolence measures. Third, the mediational model tested is based on correlational data and therefore does not provide data on causal relations. Longitudinal research would be useful in exploring causal links among the variables investigated. Fourth, future research should move beyond self-report and attempt to replicate the mediational model by using multiple methods of assessing forgiveness and conflict resolution, such as other-report and behavioral measures. Finally, 
although we took into account cross-partner effects, forgiveness was still analyzed individually, and not as an interpersonal process which implies interactions between partners. For example, we did not analyze the offending partner's reactions following the offense. Yet, it can be argued that the perceptions of effective arguing and relationship quality depend not only on the victim's ability to overcome the offense but also on the ways the offending partner reacts to it. In fact, the extent to which an offending partner shows regret for what he/she has done or apologizes is likely to affect the other partner's perception of effective arguing and relationship quality (see McCullough et al., 1998).

Notwithstanding these limitations, the present study is among the first to examine the role of forgiveness in couple conflict resolution. The pattern of results is consistent with the idea that overcoming avoidant and revengeful intentions and being benevolent towards the partner are effective strategies to handle conflict that originates from partner offences. The findings may also be relevant for clinical work with couples. Specifically, they suggest that including forgiveness-promoting interventions in the context of couple therapy is likely to be effective when the couples' present arguing is rooted in past partner transgressions.

\section{References}

Aiken, L. S., \& West, S. G. (1991). Multiple regression: testing and interpreting interactions. London: Sage.

Akaike, H. (1973). Information theory as an extension of the maximum likelihood principle. In B. N. Petrov \& F. Csaki (Eds.), Second International Symposium on Information Theory. Akademiai Kiado, Budapest.

Amato, P. R. \& Rogers, S. J. (1997). A longitudinal study of marital problems and subsequent divorce. Journal of Marriage and the Family, 59, 612-624

Bagozzi, R. P. \& Heatherton, T. F. (1994). A general approach to representing multifaceted personality constructs: Application to self esteem. Structural Equation Modeling, 1(1), 35-67.

Barber, L., Maltby, J. \& Macaskill, A. (2005). Angry memories and thoughts of revenge: The relationship between forgiveness and anger rumination. Personality and Individual Differences, 39, 253-262.

Beach, S. R. H. (2001). Expanding the study of dyadic conflict: The potential role of self-evaluation maintenance processes. In A. Booth, A. C. Crouter \& M. Clements (Eds.), Couples in conflict. Mahwah: LEA.

Beach, S. R. H., Kamen, C. \& Fincham, F. D. (2006). Marital dysfunction. In F. Andrasik (Ed.), Comprehensive Handbook of Personality and Psychopathology: Volume II, Adult Psychopathology (pp. 450-468). New York: Wiley.

Bentler, P. M. (1986). Lagrange Multiplier and Wald tests for EQS and EQS/PC. Los Angeles: BMDP Statistical Software.

Bentler, P. M. (1990). Comparative fit indices in structural models. Psychological Bulletin, 107, 238-246.

Bentler, P. M. (1995). EQS Structural Equations Program Manual, Multivariate Software. Encino.

Bentler, P. M. \& Chou, C. (1987). Practical issues in structural modeling. Sociological Methods and Research, 16, 78-117.

Bertoni, A. \& Bodenmann, G. (2006). Positive and negative dimensions, conflict styles and relationships with family of origin in satisfied and dissatisfied couples. Manuscript submitted for publication.

Bollen, K. A. (1980). Issues in the comparative measurement of political democracy. American Sociological Review, 45, 370-390.

Booth, A., Crouter, A. C. \& Clements, M. (2001). Couples in conflict. Mahwah: LEA.

Bowman, M. L. (1990). Coping efforts and marital satisfaction: Measuring marital coping and its correlates. Journal of Marriage and the Family, 52(2), 463-474.

Bradbury, T. N., Rogge, R. \& Lawrence, E. (2001). Reconsidering the role of conflict in marriage. In A. Booth, A. C. Crouter \& M. Clements (Eds.), Couples in conflict (pp. 59-82). Mahwah: LEA.

Brewer, M. B \& Gardner, W. (1996). Who is this „We“? Levels of collective identity and self representations. Journal of Personality and Social Psychology, 71, 83-93.

Browne, M. W. \& Cudeck, R. (1993). Alternative ways of assessing model fit. In K. A. Bollen \& J. S. Long 
(Eds.), Testing structural equation models (pp. 136162). Newbury Park, CA: Sage.

Burman, B., John, R. S. \& Margolin, G. (1992). Observed patterns of conflict in violent, nonviolent, and nondistressed couples. Behavioral Assessment, $14,15-37$.

Christensen, A. \& Heavy, C. L. (1990). Gender and social structure in the demand/withdraw pattern of marital interaction. Journal of Personality and Social Psychology, 59, 73-81.

Cordova, J. V. \& Dorian, M. (2004). Observing intimacy in couples' interactions. In P. K. Kerig \& D. Baucom (Eds.), Couple observational coding systems. Mahwah, NJ: Lawrence Erlbaum Associates.

Cotterell, N., Eisenberger, R. \& Speicher, H. (1992). Inhibiting effects of reciprocation wariness on interpersonal relationships. Journal of Personality and Social Psychology, 62, 658-668.

Cross, S. E. \& Madson, L. (1997). Models of the Self: Self-construals and gender. Psychological Bulletin, 122, 5-37.

Eaton, J. \& Struthers, C. W. (2006). The reduction of psychological aggression across varied interpersonal contexts through repentance and forgiveness. Aggressive Behavior, 32, 1-12.

Enright, R. D., Freedman, S. \& Rique, J. (1998). The psychology of interpersonal forgiveness. In R. D. Enright \& J. North (Eds.), Exploring Forgiveness (pp. 46-63). Madison, WI: University of Wisconsin Press.

Epstein, N., Baucom, D. H. \& Rankin, L. A. (1993). Treatment of marital conflict: A cognitivebehavioral approach. Clinical Psychology Review, $13,45-57$

Feeney, J. A. (2005). Hurt feelings in couple relationships: Exploring the role of attachment and perceptions of personal injury. Personal Relationships, 12, 253-271.

Feeney, J. A. \& Hill, A. (2006). Victim-perpetrator differences in reports of hurtful events. Journal of Social and Personal Relationships, 23, 587-608.

Fincham, F. D. (2000). The kiss of porcupines: From attributing responsibility to forgiving. Personal Relationships, 7, 1-23.
Fincham, F. D. \& Beach, S. R. H. (1999). Conflict in marriage: Implications for working with couples. Annual Review of Psychology, 50, 47-77.

Fincham, F. D. \& Beach, S. R. (2002). Forgiveness in marriage: Implications for psychological aggression and constructive communication. Personal Relationships, 9, 239-251.

Fincham, F. D., Beach, S. R. \& Davila, J. (2004). Forgiveness and conflict resolution in marriage. Journal of Family Psychology, 18, 72-81.

Fincham, F. D., Hall, J. H. \& Beach, S. R. H. (2005). Till lack of forgiveness doth us part: Forgiveness in marriage. In E. L. Worthington (Ed.), Handbook of forgiveness (pp. 207-226). New York: Routledge.

Fincham, F. D., Hall, J. H. \& Beach, S. R. H. (2006). Forgiveness in marriage: Current status and future directions. Family Relations, 55, 415-427.

Fincham, F. D., Harold, G. \& Gano-Phillips, S. (2000). The longitudinal relation between attributions and marital satisfaction: Direction of effects and role of efficacy expectations. Journal of Family Psychology, 14, 267-285.

Gleason, M. E. J., Iida, M., Bolger, N. \& Shrout, P. E. (2003). Daily supportive equity in close relationships. Personality and Social Psychology Bulletin, 29, 1036-1045.

Goeke-Morey, M. C., Cummings, E. M., Harold, G. T. $\&$ Shelton, K. H. (2003). Categories and continua of destructive and constructive marital conflict tactics from the perspective of Welsh and US children. Journal of Family Psychology, 17, 327-338.

Gordon, K. C. \& Baucom, D. H. (2003). Forgiveness and marriage: Preliminary support for a measured based on a model of recovery from a marital betrayal. American Journal of Family Therapy, 31,179-199.

Gottman, J. M. (1979). Marital interaction. New York: Academic Press.

Gottman, J. M. (1998). Psychology and the study of marital processes. Annual Review of Psychology, 49, 169-179.

Gottman, J. M. \& Krokoff, L. J. (1989). Marital interaction and satisfaction: A longitudinal view. Journal of Consulting and Clinical Psychology, 57, 47-52. 
Gouldner, A. W. (1960). The norm of reciprocity: A preliminary statement. American Sociological Review, 25, 161-178.

Guglielmetti, C., Iafrate, R. \& Lanz, M. (1997). Stili ed esiti di conflitto coniugale: differenze di genere e di prospettiva [Styles and outcomes of conjugal conflict: Differences in gender and perspective]. Archivio di Psicologia, Neurologia e Psichiatria, 58, 599-610.

Heavey, C. L., Layne, C. \& Christensen, A. (1993). Gender and conflict structure in marital interaction: A replication and extension. Journal of Consulting and Clinical Psychology, 61, 16-27.

Honess, T. M. \& Charmann, E. A. (1992). Conflict Scales for divorcing and intact parents. Unpublished scales. University of Wales, Cardiff.

Hoyt, W. T., Fincham, F. D., McCullough, M. E., Maio, G. \& Davila, J. (2005). Responses to interpersonal transgression in family: Forgivingness, forgivability and relationship-specific effects. Journal of Personality and Social Psychology, 89(3), 375-394.

Huston, T. L. \& Vangelisti, A. (1991). Socioemotional behavior and satisfaction in marital relationships. Journal of Marriage and the Family, 44, 901-925.

Jöreskog, K. G. \& Sörbom, D. (1984). LISREL VI user's guide. Mooresville, IN: Scientific Software.

Julien, D., Markmann, H. J. \& Lindahl, K. M. (1989). A comparison of a global and microanalytic coding system: Implication for the future trends in studying interactions. Behavioral Assessment, 11, $81-100$.

Kachadourian, L. K., Fincham, F. \& Davila, J. (2004). The tendency to forgive in dating and married couples: The role of attachment and relationship satisfaction. Personal Relationships, 11, 373-393.

Kahn, J., Coyne, J. C. \& Margolin, G. (1985). Depression and marital conflict: The social construction of despair. Journal of Social and Personal Relationships, 2, 447-462.

Karremans, J. C. \& Van Lange, P. A. M. (2004). Back to caring after being hurt: The role of forgiveness. European Journal of Social Psychology, 34, 207-227.

Karremans, J. C., Van Lange, P. A. M., Ouwerkerk, J. W. $\&$ Kluwer, E. S. (2003). When forgiving enhances psychological well-being: The role of interperso- nal commitment. Journal of Personality and Social Psychology, 84, 1011-1026.

Kelly, H. H. (1983). Analyzing close relationships. In H. H. Kelly, E. S. Brescheid, A. Christensen, J. Harvey, T. L. Huston, E. McClintock, L. A. Peplau $\&$ D. R. Peterson (Eds.), Close relationships (pp. 20-67). New York: W. H. Freeman.

Kelly, H. H. \& Thibaut, J. W. (1978). Interpersonal relationships: A theory of interdependence. New York: Wiley Interscience.

Kerig, P. K. (1996). Assessing the links between interparental conflict and child adjustment: The Conflicts and Problem-solving Scales. Journal of Family Psychology, 10(4), 454-473.

Klein, R. \& Johnson, M. P. (1997). Strategies of couple conflict. In Duck, S. (Ed), Handbook of personal relationships: Theory, research and interventions ( $2^{\text {nd }}$ ed., pp. 469-486). New York: John Wiley \& Sons.

Kluwer, E. S., Heesink, J. A. M. \& Van de Vliert, E. (1997). The marital dynamics of conflict overt the division of labor. Journal of Marriage and the Family, 59, 635-653.

Kurdek, L. A. (1994). Conflict resolution styles in gay, lesbian, heterosexual non parent, and heterosexual parent couples. Journal of Marriage and the Family, 56, 705-722.

Kurdek, L. A. (1995). Predicting change in marital satisfaction from husbands' and wives' conflict resolution styles. Journal of Marriage and the Family, 57, 153-164.

Laurenceau, J. P., Barrett, L. F. \& Rovine, M. J. (2005). The interpersonal process model of intimacy in marriage: A daily-diary and multilevel modeling approach. Journal of Family Psychology, 19, 314 323.

Lawler, K. A., Younger, J. W., Piferi, R. L., Billington, E., Jobe, R., Edmondson, K. \& Jones, W. H. (2003). A change of heart: Cardiovascular correlates of forgiveness in response to interpersonal conflict. Journal of Behavioral Medicine, 26, 373-393.

Leonard, K. E. \& Roberts, L. J. (1998). Marital aggression, quality, and stability in the first year of marriage: Findings from the Buffalo Newlywed Study. In T. N. Bradbury (Ed.), The developmental course of marital dysfunction (pp. 44-73). Cambridge, England: Cambridge University Press. 
Markman, H. J. (1987). The prediction and prevention of marital distress: Summary of results. Unpublished manuscript. University of Denver, Center for Marital and Family Studies, Denver.

Markus, H. \& Kitayama, S. (1991). Culture and the self: Implications for cognition, emotion, and motivations. Psychological Review, 98, 224-253.

McCullough, M. E., Pargament, K. I. \& Thoresen, C. E. (2000). The psychology of forgiveness: History, conceptual issues, and overview. In M. E. McCullough, K. I. Pargament \& C. E. Thoresen (Eds.), Forgiveness. Theory, research and practice (pp. 1-14). New York: Guilford Press.

McCullough, M. E., Rachal, K. C., Sandage, S. J., Worthington, Jr. E. L., Brown, S.W. \& Hight, T. L. (1998). Interpersonal forgiving in close relationships: II. Theoretical elaboration and measurement. Journal of Personality and Social Psychology, $75,1586-1603$.

McCullough, M. E., Worthington, Jr. E. L. \& Rachal, K. C. (1997). Interpersonal forgiving in close relationships. Journal of Personality and Social Psychology, 73, 321-336.

Noller, P., Feeney, J. A., Bonnell, D. \& Callan, V. J. (1994). A longitudinal study of conflict in early marriage. Journal of Social and Personal Relationships, 11, 233-252.

Norton, R. (1983). Measuring marital quality: A critical look at the dependent variable. Journal of Marriage and the Family, 45, 141-151.

Paleari, F. G., Regalia, C. \& Fincham, F. D. (2005). Marital quality, forgiveness, empathy, and rumination: A longitudinal analysis. Personality and Social Psychology Bulletin, 31(5), 1-11.

Paleari, F.G., Regalia, C. \& Fincham, F.D. (2009). Measuring offence-specific forgiveness in marriage: The Marital Offence-specific Forgiveness Scale (MOFS). Psychological Assessment, 21 (2), 194-209.

Park, Y. O. \& Enright, R. D. (1997). The development of forgiveness in the context of adolescent friendship conflict in Korea. Journal of Adolescence, 20, 393-402.

Reese-Weber, M. \& Bartle-Haring, S. (1998). Conflict resolution styles in family subsystem and adoles- cent romantic relationships. Journal of Youth and Adolescence, 27(6), 735-752.

Revenstorf, D., Vogel, B., Wegener, C., Halweg, K. \& Schindler, L. (1980). Escalation phenomena in interaction sequences: An empirical comparison in distressed and nondistressed couples. Behavior Analysis and Modification, 2, 97-116.

Rye, M. S. \& Pargament, K. I. (2002). Forgiveness and romantic relationships in college: Can it heal the wounded heart? Journal of Clinical Psychology, 58, 419-441.

Snyder, D. K. (1981). Manual for the Marital Satisfaction Inventory. Los Angeles: Western Psychological Services.

Sobel, M. E. (1987). Direct and indirect effects in linear structural equation models. Sociological Methods and Research, 16, 155-176.

Subkoviak, M. J., Enright, R. D. \& Wu, C. R. (1992, October). Current developments related to measuring forgiveness. Paper presented at the annual meeting of the Mid-Western Educational Research Association, Chicago.

Subkoviak, M. J., Enright, R. D., Wu, C., Gassin, E. A., Freedman, S., Olson, L. M. \& Sarinopoulos, I. C. (1995). Measuring interpersonal forgiveness in late adolescence and middle adulthood. Journal of Adolescence, 18, 641-655.

Tsang, J., McCullough, M. E. \& Fincham, F. (2006). The longitudinal association between forgiveness and relationship closeness and commitment. Journal of Social and Clinical Psychology, 25 (4), 448-472.

Veroff, J., Young. A. M. \& Coon, H. M. (1997). The early years of marriage. In S. Duck (Ed.), Handbook of personal relationships: Theory, research and interventions ( $2^{\text {nd }}$ ed., pp. 431-450). Chichester, England: Wiley.

Worthington, E. L., Jr. (2005). Handbook of forgiveness. New York: Routledge.

Zechmeister, J. S. \& Romero, C. (2002). Victim and offender accounts of interpersonal conflict: Autobiographical narratives of forgiveness and unforgiveness. Journal of Personality and Social Psychology, $82,675-686$. 